\title{
Development and Testing of High Current Hollow Cathodes for High Power Hall Thrusters
}

\author{
Hani Kamhawi ${ }^{*}$, and Jonathan Van Noord ${ }^{\dagger}$ \\ NASA Glenn Research Center at Lewis Field, Cleveland, Ohio, 44135
}

\begin{abstract}
NASA's Office of the Chief Technologist In-Space Propulsion project is sponsoring the testing and development of high power Hall thrusters for implementation in NASA missions. As part of the project, NASA Glenn Research Center is developing and testing new high current hollow cathode assemblies that can meet and exceed the required discharge current and life-time requirements of high power Hall thrusters. This paper presents test results of three high current hollow cathode configurations. Test results indicated that two novel emitter configurations were able to attain lower peak emitter temperatures compared to state-of-the-art emitter configurations. One hollow cathode configuration attained a cathode orifice plate tip temperature of $1132{ }^{\circ} \mathrm{C}$ at a discharge current of $100 \mathrm{~A}$. More specifically, test and analysis results indicated that a novel emitter configuration had minimal temperature gradient along its length. Future work will include cathode wear tests, and internal emitter temperature and plasma properties measurements along with detailed physics based modeling.
\end{abstract}

\section{Nomenclature}

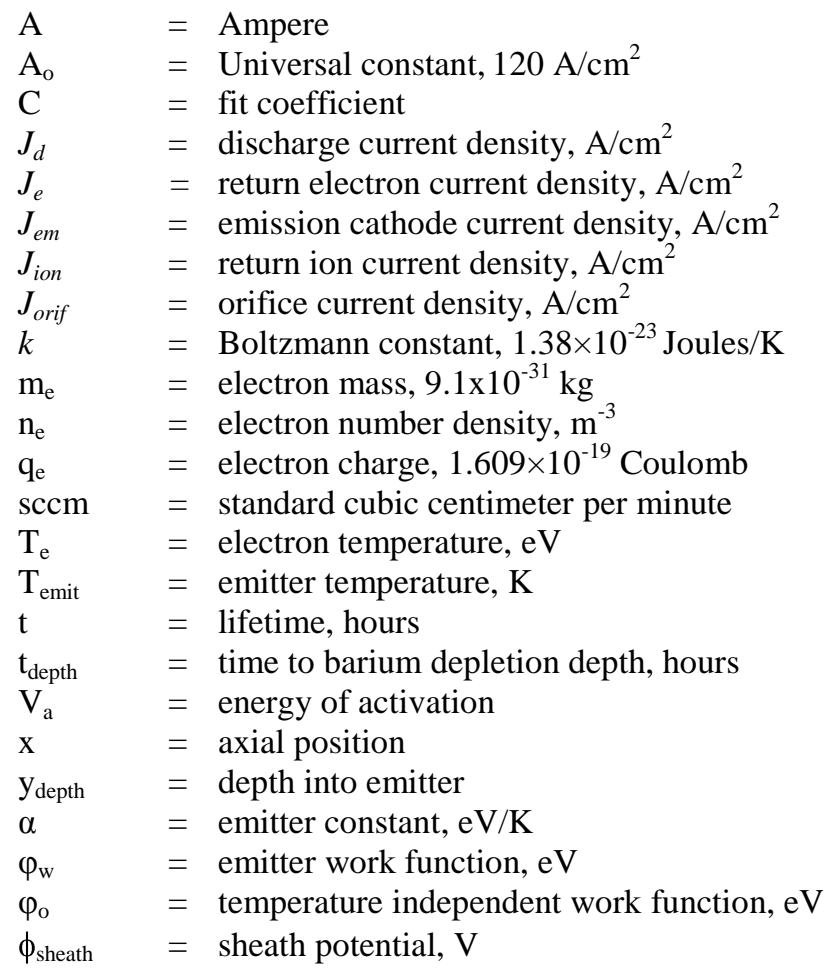

\footnotetext{
* Aerospace Engineer, Propulsion and Propellants Branch, hani.kamhawi-1@ nasa.gov, Associate AIAA Fellow.

${ }^{\dagger}$ Aerospace Engineer, Propulsion and Propellants Branch, jonathan.l.vannoord@ nasa.gov, Senior AIAA Member.
} 


\section{Introduction}

$\mathrm{H}$ igh power electric propulsion (EP) systems are enabling and enhancing for time critical missions or missions requiring transportation of large payloads. A number of mission studies were performed, highlighting the enhancing and enabling features of high power EP systems for reusable space tug applications for transfer of payloads from low-earth-orbit to geosynchronous-earth-orbit and for use in Mars mission scenarios. ${ }^{1,2,3}$

NASA Glenn Research Center (GRC) has a long history of researching and developing high power Hall thrusters and high power ion engines. NASA GRC has built and tested a number of high power Hall thrusters including the NASA-457Mv1, NASA-400M, NASA-457Mv2, and NASA-300M. ${ }^{4,5,6,7,8}$ The NASA-457Mv1\&2 Hall thrusters were designed to operate a power levels of $50 \mathrm{~kW}$ and higher with maximum sustainable discharge currents of 100 A. The NASA-400M was designed to operate at power levels greater than $40 \mathrm{~kW}$ with a maximum discharge current of approximately $100 \mathrm{~A}$. The NASA-300M was designed to operate at a maximum power level of $20 \mathrm{~kW}$ with peak discharge current of approximately 50 A. During these thruster development activities, NASA GRC was also pursuing the development of long life cathode high current hollow cathode assemblies that support the aforementioned thruster developments. Unfortunately, the programs which funded the high power Hall thruster developments were terminated in early 2004.

National interest in high power EP systems has been renewed. In 2010, NASA's Human Exploration Framework Team (HEFT) concluded that the use of a high power (i.e. on the order of $300 \mathrm{~kW}$ ) solar electric propulsion (SEP) system could significantly reduce the number of heavy lift launch vehicles required for a human mission to a near earth asteroid. ${ }^{9}$ Hall thrusters are ideal for such applications because of their high power processing capabilities and their efficient operation at moderate specific impulses, which leads to reduced trip times for such missions. ${ }^{10}$

NASA's Human Exploration and Operations Mission Directorate (HEOMD) Enabling Technology Development and Demonstration (ETDD) Program was focused on developing, maturing, testing, and demonstrating the technologies needed to reduce the cost and expand the capability of future space exploration activities. The ETDD program content included performing foundational research and studying of the requirements and potential designs for advanced, high energy in-space propulsion systems. These high energy propulsion systems were intended to support deep-space human exploration and reduce travel time between Earth's orbit and future destinations for human activity. This would enable a new space transportation capability via a SEP stage. The SEP stage could enable cost effective missions within Earth orbit, near earth objects, and deep space robotic science missions. Although, the ETDD program has recently transitioned to the NASA's Office of the Chief Technologist (OCT), the program content remained and is still focused on developing and maturing the high power propulsion technologies needed to enhance the agency's capabilities to explore and move large payloads in space. NASA GRC's fiscal year 2012 high power Hall development activities were focused on:

- Testing of existing high power Hall thrusters (NASA-300M and NASA-457M-v2);

- Designing, fabricating, and testing high current cathode assemblies with an emission current capability $\geq$ $100 \mathrm{~A}$ and lifetime capability greater than 30,000 hours;

- Developing plasma diagnostics for Hall thrusters;

- Performing Hall thruster physics based modeling with JPL; and

- Performing Hall thruster structural and thermal modeling.

This paper is focused on a recent activity to develop a long life, high current hollow cathode. The paper is organized as follows: Section II presents a brief review of past high current cathode development and testing activities at NASA GRC. Section III discusses emitter life and target peak emitter temperatures required for emitter life beyond 30,000 hours. Section IV presents the experimental apparatus including facilities and tested hollow cathode configurations. Section V presents the experimental results. Section VI presents a discussion of the experimental results. Section VII summarizes the conclusions from this study and discuss future cathode development, testing, and modeling efforts.

\section{Past High Current Hollow Cathode Development at NASA GRC}

NASA GRC has a long history of researching and developing hollow cathode assemblies (HCAs) for implementation with ion thrusters, Hall thrusters, and plasma contactors. NASA GRC HCAs have been integrated with laboratory, engineering development, and flight thrusters. NASA GRC-developed HCAs are used aboard the International Space Station (ISS) plasma contactor units. The ISS HCA development included performing a life-test on one configuration to confirm that the emitter had the lifetime capability to meet the ISS plasma contactor unit life requirements. ${ }^{11}$ The ISS HCAs design approach and methodology has been incorporated in a number of HCAs that 
have been and are currently being used on engineering development unit Hall and ion thrusters. More specifically, NASA GRC-developed HCAs have demonstrated in excess of 42,000 hours of operation during the NASA Evolutionary Xenon Thruster (NEXT) long duration test (LDT). ${ }^{12}$ In the NEXT LDT, two HCAs are employed, and they include a discharge cathode assembly (DCA) and a neutralizer cathode assembly (NCA). The DCA operates at emission currents $<20 \mathrm{~A}$ and the NCA operates at emission currents $\leq 6.5 \mathrm{~A}$.

High current cathode development and testing at NASA GRC started in 1987. NASA GRC achieved cathode operation up to $110 \mathrm{~A}$ with minimal cathode erosion, however, the tested cathode configurations exhibited high emitter temperatures. ${ }^{13}$ In 2001, NASA GRC published testing results of a laboratory 100 A HCA. ${ }^{14}$ The results indicated that at an emission current of $100 \mathrm{~A}$, the cathode orifice plate tip temperature was between $1360{ }^{\circ} \mathrm{C}$ and $1400{ }^{\circ} \mathrm{C}$. In 2005 , another effort was undertaken to demonstrate a 100 A HCA that can have a long life capability and that can operate at temperatures lower than the temperatures demonstrated by the $2001 \mathrm{HCA} .{ }^{15}$ Several configurations were assembled and tested. The best performing configuration demonstrated an orifice plate tip temperature between $1300{ }^{\circ} \mathrm{C}$ and $1320{ }^{\circ} \mathrm{C}$ at $100 \mathrm{~A}$. Also in 2005, Van Noord et al. demonstrated a high current hollow cathode that operated at a 50 A discharge current with a peak cathode orifice plate tip temperature of approximately $1100{ }^{\circ} \mathrm{C}$ at $19 \mathrm{sccm} .{ }^{16}$

\section{Emitter Lifetime}

The goal of the high current hollow cathode development at NASA GRC is to design, manufacture, and test a laboratory HCA that can generate a sustained discharge current of 100 A. A high current hollow cathode with a lifetime capability in excess of 30,000 hours is desired. The lifetime capability of a hollow cathode is mainly governed by the emitter life and by the sputter erosion of key components, namely cathode orifice plate and keeper orifice plate. Other factors affecting cathode life include the heater reliability. Once a reliable hollow cathode configuration is finalized, the heater and cathode manufacturing and testing procedures that have been developed at NASA GRC over the past 30 years can be fully leveraged to arrive at a high fidelity HCA that can be subjected to extended duration testing.

The lifetime of the hollow cathode emitter is a strong function of the emitter operating temperature. An estimate of the emitter surface operating temperature is typically made by using the Richardson-Duchman equation: ${ }^{17}$

$$
J_{e m}=A_{o} T_{e m i t} e^{\frac{-q_{e} \varphi_{w}}{k T_{e m i t}}}
$$

Here $J_{e m}$ is the emission current density in $\mathrm{A} / \mathrm{cm}^{2}, \mathrm{~A}_{\mathrm{o}}$ is a universal constant with a value of $120 \mathrm{~A} / \mathrm{cm}^{2}, T_{\text {emit }}$ is the emitter temperature in $\mathrm{K}, \mathrm{q}_{e}$ is the electron charge $\left(1.609 \times 10^{-19} \mathrm{C}\right), k$ is the Boltzmann constant $\left(1.381 \times 10^{-23} \mathrm{~J} / \mathrm{K}\right), \varphi_{w}$ is emitter work function in $\mathrm{eV}\left(\varphi_{w}=\varphi_{o}+\alpha \mathrm{T}_{\text {emit }}\right.$ where $\varphi_{o}$ is the temperature independent work function, and $\alpha$ is an experimentally measured constant). The work function is determined by the impregnate composition. Table 1 presents a summary of work function values for various impregnate compositions. Figure 1 details how the emitter current density varies with emitter temperature for the various impregnate compositions listed in Table 1. For this round of cathode testing, a porous tungsten emitter impregnated with the 4:1:1 composition $\left(4 \mathrm{BaO}: \mathrm{CaO}: \mathrm{Al}_{2} \mathrm{O}_{3}\right)$ is used. However, it is anticipated that once preliminary testing has been completed, 6:1:2x (x refers to scandium) impregnate composition will be investigated because it has a lower work function than the 4:1:1 or 6:1:2 impregnate compositions and is more resistant to oxygen poisoning.

Table 1: Work function of various porous tungsten impregnate composition and lanthanum hexaboride.

\begin{tabular}{|c|c|c|}
\hline Impregnate Composition & Work Function, eV & $\begin{array}{c}\text { Work function } \\
@ 1373.15 \mathrm{~K}, \mathrm{eV}\end{array}$ \\
\hline $4: 1: 1,6: 1: 2$ & $1.67+0.000282 \mathrm{~T}$ & 1.97 \\
\hline $5: 3: 2$ & $1.67+0.000573 \mathrm{~T}$ & 2.01 \\
\hline $4: 1: 1 \mathrm{x}, 6: 1: 2 \mathrm{x}$ & $1.43+0.000401 \mathrm{~T}$ & 1.86 \\
\hline $5: 3: 2 \mathrm{x}$ & $1.43+0.000436 \mathrm{~T}$ & 1.90 \\
\hline $\mathrm{LaB}_{6}$ & $2.66+0.000123 \mathrm{~T}$ & 2.79 \\
\hline
\end{tabular}

A first order estimate for hollow cathode emitter life can be obtained by using the known temperature and lifetime data from planar cathodes. The model used in this paper is based on a relationship outlined by Palluel and Shroff that is shown below. ${ }^{18}$ 


$$
\ln (t)=C+q e^{V_{a}} / k T_{\text {emit }}
$$

Here $C$ is an empirically derived fit coefficient, and $V_{a}$ is energy of activation. This model examines the relationship between cathode lifetime and emitter temperature. This model is developed based on data from impregnated planar cathodes that are used in the vacuum industry. As a result of operating at a lower emitter temperature, the impregnate depletion rates in the emitter are reduced, which increases emitter lifetime. ${ }^{19}$ Reference 19 further elaborates on the model to determine the time to a particular barium depletion depth within impregnated an emitter. This relationship is given in Eq. 3 and relates the time to a particular depth, $y_{\text {depth }}$, as a function of the time to a depletion depth of $100 \mu \mathrm{m}, \mathrm{t}_{100 \mu \mathrm{m}}$.

$$
t_{\text {depth }}=t_{100 \mu \mathrm{m}}\left(y_{\text {depth }} /{ }_{100 \mu \mathrm{m}}\right)^{2}
$$

While model error is difficult to estimate, the model provides a starting point for a design.

While Eq. 3 provides a life estimate to any depth, there is likely a depth where the impregnate will no longer be accessible. At the completion of the NASA Solar Electric Propulsion Technology Application Readiness (NSTAR) extended life test (ELT), which operated for 30,000+ hours, both the neutralizer and discharge cathodes were still operational. ${ }^{20}$ Measurements taken to determine barium depletion in the emitters were only to a depth of $500 \mu \mathrm{m}$. The ELT results showed some barium depletion at a depth of up to $300 \mu \mathrm{m}$ at the downstream end of the emitter, but not at $500 \mu \mathrm{m}$. Based on those measurements, that barium is

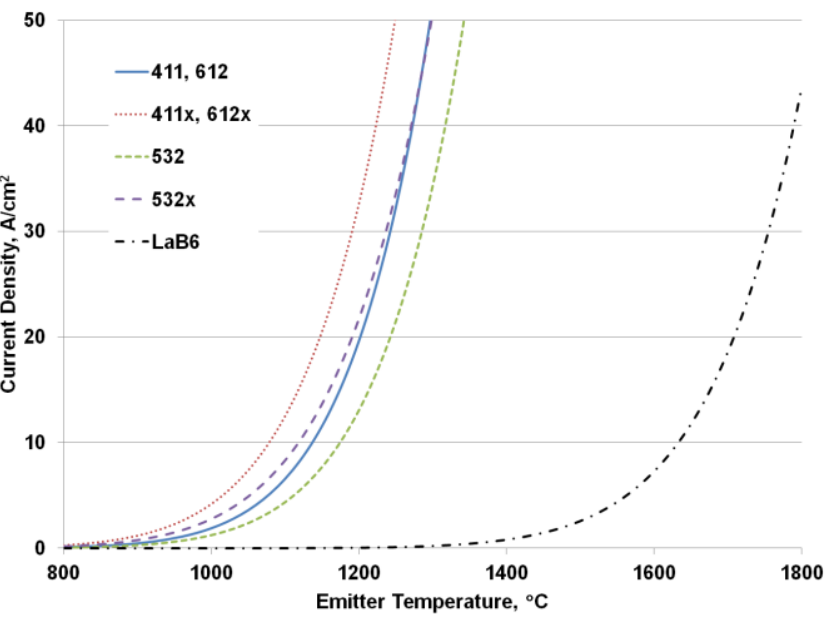

Figure 1. Current density profiles for various emitter impregnate compositions and lanthanum hexaboride. accessible to at least a $300 \mu \mathrm{m}$ depth. Figure 2 shows the relationship between emitter temperature and lifetime for the $300 \mu \mathrm{m}$ depletion depth as derived from the above model. In order to achieve a lifetime greater than 30,000 hours, the emitter temperature must be between 1100 to $1150{ }^{\circ} \mathrm{C}$. This is consistent with the recommended operating temperature of 950 to $1150{ }^{\circ} \mathrm{C}$ for a long life impregnated emitter. ${ }^{21}$

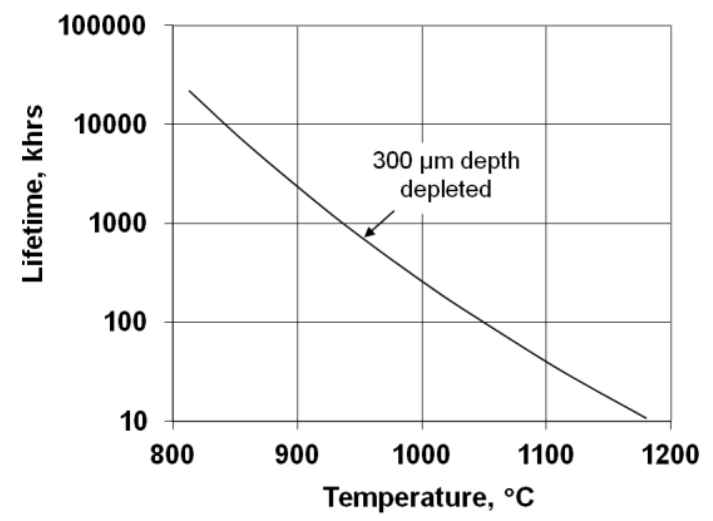

Figure 2. Emitter lifetime estimate vs. emitter temperature for $300 \mu \mathrm{m}$ barium depletion depth. 


\section{Experimental Apparatus}

\section{A. Vacuum Facilities}

Hollow cathode testing was performed in vacuum facility 8 (VF-8). Vacuum facility 8 is a $1.5-\mathrm{m}$ diameter by 4.7-m long cylindrical tank with a pumping speed in excess of 160,000 liters per second (air) provided by four 0.9-m diameter oil diffusion pumps. The pressure prior to cathode operation was approximately $2 \times 10^{-7}$ torr and this increased to approximately $3.5 \times 10^{-5}$ torr at a cathode flow rate of approximately $70 \mathrm{sccm}$.

\section{B. Hollow Cathode Assemblies}

Three HCAs, designated configurations 1, 2, and 3, were manufactured and tested. Configurations 1 and 2 are shown in Figure 3. The cathode tube size and keeper orifice plate dimensions for configurations 1 and 2 were identical, however, the cathode plate orifice diameter for configuration 2 is 17\% larger than that of configuration 1. Also, configuration 1 utilized a state-of-the-art (SOA) emitter configuration while configuration 2 utilized a novel emitter geometry that is $33 \%$ shorter than that of configuration 1 emitter. Due to the large size of the cathode tube, both configurations used two sheathed heaters that were powered by two separate heater power supplies. Configuration 3 HCA geometry, shown in Figure 4, is identical to the NEXT DCA except for that it employs a novel emitter configuration whose configuration is different than configuration 2 emitter. Configuration 3 used one sheathed heater that is identical to the heater used in the NEXT DCA. All three cathode configurations were fitted with a keeper electrode that was used for cathode discharge initiation. All three configurations were equipped with at least one type-R thermocouple to monitor the cathode orifice plate tip temperature.

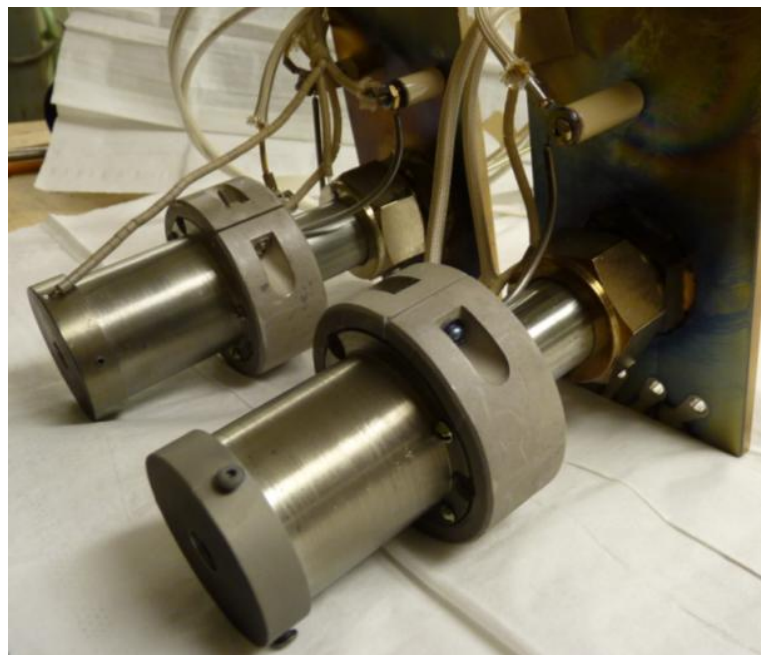

Figure 3. Photograph of configurations 1 and 2.

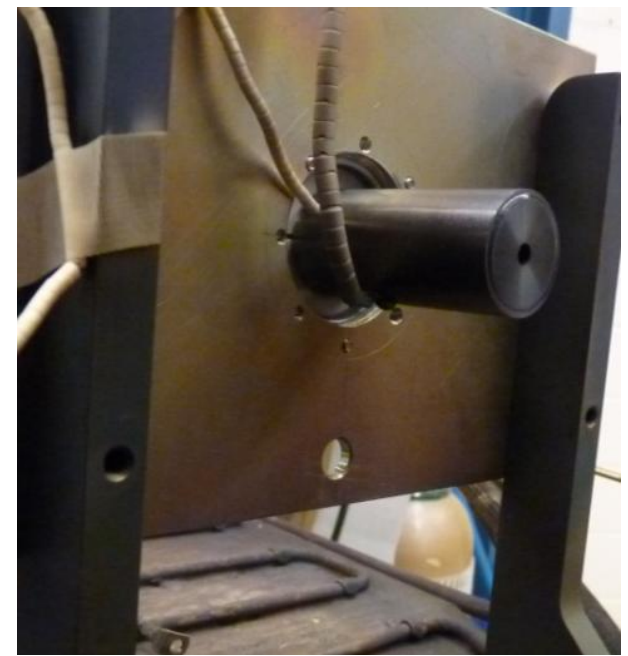

Figure 4. Photograph of configuration 3 mounted on the test stand.

\section{Power Supplies}

A discharge supply capable of producing a constant voltage output ranging from $0-60 \mathrm{~V}$ at current levels of 0 250 A operated the main discharge. Two heater and one keeper power supplies were used during configurations 1 and 2 testing, while configuration 3 required only one heater power supply. An ignition power supply that was capable of operating at voltages up to $600 \mathrm{~V}$ was used for cathode ignition.

\section{Flow System}

A laboratory xenon feed system was used in the series of tests. A $100 \mathrm{sccm}$ mass flow controller provided xenon to the cathode. The mass flow controller was calibrated using a commercially available volumetric flow rate calibration system. 


\section{Experimental Results}

\section{A. Configuration 1}

Configuration 1 testing was performed for emission currents between 50 and $150 \mathrm{~A}$ at $25 \mathrm{~A}$ increments. A $20 \mathrm{~cm}$ diameter cylindrical molybdenum anode was placed $20 \mathrm{~cm}$ from the cathode keeper plate. The anode center line was aligned with the cathode centerline. The results reported in the study were obtained for steady state operation. Steady state was achieved when the cathode orifice plate tip temperature reached a steady value. Typically, steady state operation was obtained approximately 30 to 45 minutes after the cathode was transitioned to a new operating condition. Figure 5 shows a photograph of configuration 1 setup inside VF8.

After completing cathode conditioning, cathode ignition was performed by powering the two heater elements to approximately $150 \mathrm{~W}$ each for approximately 8 minutes. Then high voltage was applied across the keeper and xenon flow was initiated. Once ignited, the cathode was operated at a keeper current of $4 \mathrm{~A}$ and a discharge current of approximately $25 \mathrm{~A}$ for 20 minutes. Then, the keeper current was set to zero and the keeper voltage was allowed to float.

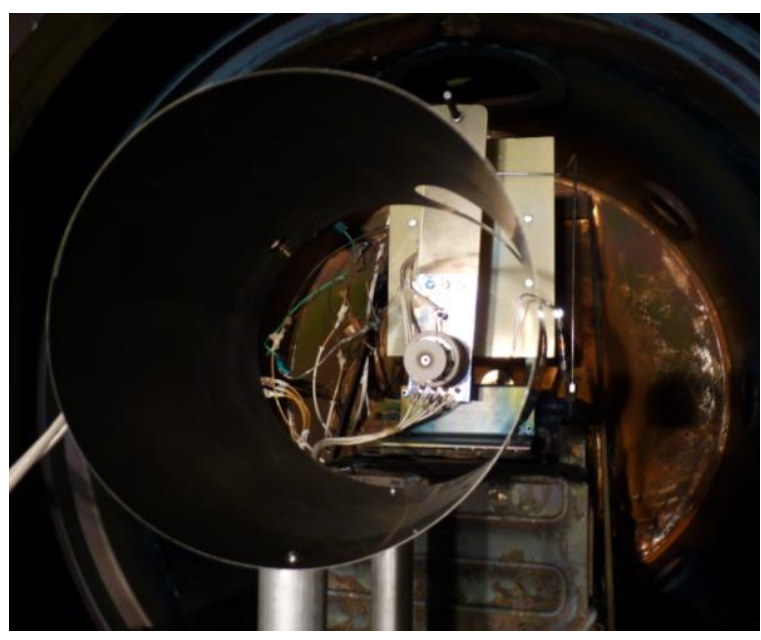

Figure 5. Photograph of configuration 1 mounted inside VF8 with cylindrical molybdenum anode.

During the test campaign, the following readings were recorded: discharge current, discharge voltage, keeper voltage at zero keeper current, cathode-to-ground voltage, and cathode orifice plate tip temperature. Table 2 summarizes configuration 1 test conditions.

Configuration 1 accumulated approximately 70 hours of test time. More than $50 \%$ of the testing duration was performed at discharge currents $\geq 100$ A. Configuration 1 test results are presented in Figures 6, 7, and 8. Figure 6 shows the cathode orifice plate tip temperature variation with flow rate for the different discharge currents. Figure 7 shows the cathode orifice plate tip temperature variation with discharge current for the various flow rates. Figure 8, shows how the discharge voltage and cathode-to-ground voltage varied with flow rate for the various cathode discharge currents. No keeper voltage profiles are presented here since the keeper variations were minimal. During configuration 1 test campaign, the keeper voltage varied between 3 $\mathrm{V}$ and $5 \mathrm{~V}$. Monitored keeper-to-cathode voltage

1400

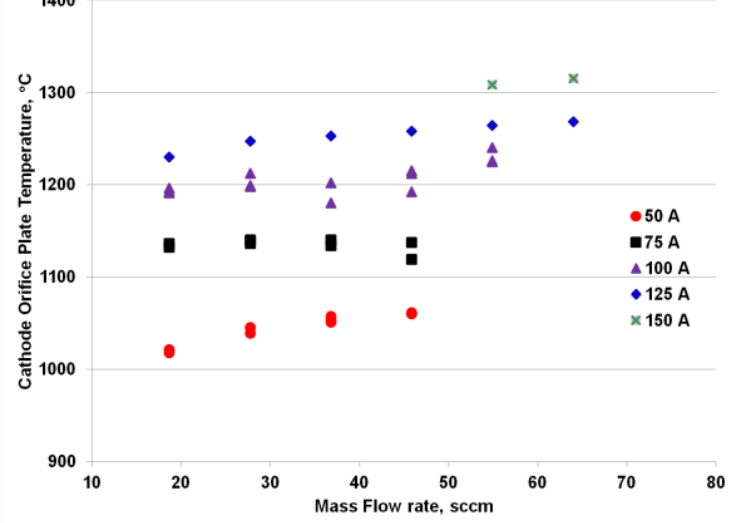

Figure 6. Configuration 1 cathode orifice plate tip temperature variation with mass flow rate for various discharge currents.

Table 2: Configuration 1 test conditions.

\begin{tabular}{|c|c|c|c|c|c|}
\hline \multirow{2}{*}{$\begin{array}{c}\text { Flow rate, } \\
\text { sccm }\end{array}$} & \multicolumn{5}{|c|}{ Discharge Current, A } \\
\cline { 2 - 6 } & 50 & 75 & 100 & 125 & 150 \\
\hline 19 & $\bullet$ & $\bullet$ & $\bullet$ & $\bullet$ & $\bullet$ \\
\hline 28 & $\bullet$ & $\bullet$ & $\bullet$ & $\bullet$ & $\bullet$ \\
\hline 37 & $\bullet$ & $\bullet$ & $\bullet$ & $\bullet$ & $\bullet$ \\
\hline 46 & $\bullet$ & $\bullet$ & $\bullet$ & $\bullet$ & $\bullet$ \\
\hline 55 & & & & $\bullet$ & $\bullet$ \\
\hline 64 & & & & $\bullet$ & $\bullet$ \\
\hline
\end{tabular}

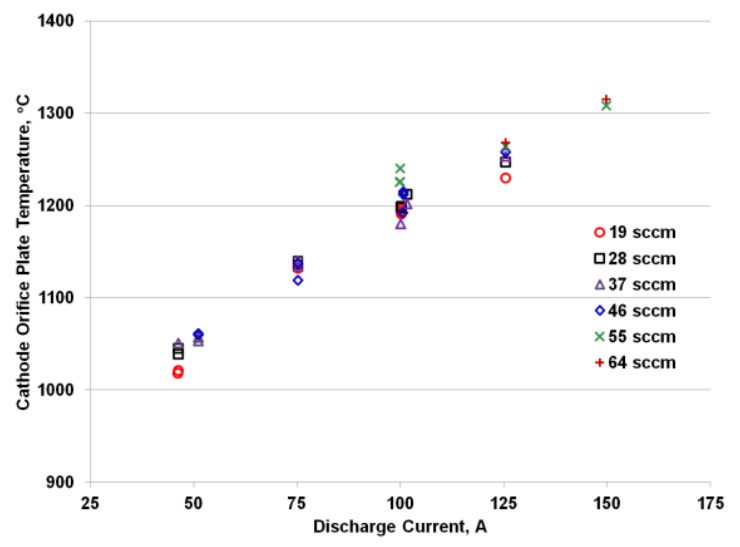

Figure 7. Configuration 1 cathode orifice plate tip temperature variation with discharge current for various mass flow rates. 
oscillations had a peak-to-peak magnitude of approximately $2 \mathrm{~V}$.

Experimental results presented in Figures 6 and 7 indicate, in general, that the cathode orifice plate tip temperature increased with increased cathode flow rate at the various operating discharge currents. For $150 \mathrm{~A}$ testing, results were collected for flow rates between $19 \mathrm{sccm}$ and $64 \mathrm{sccm}$. However, results reported in Figures 6 , 7 , and 8 are only for flow rates of $55 \mathrm{sccm}$ and $64 \mathrm{sccm}$. The results at the lower flow rates will not be reported in this paper because steady state was not achieved. Figures 6 and 7 show that for flow rates of $55 \mathrm{sccm}$ and $64 \mathrm{sccm}$, the cathode orifice plate tip temperatures were $1308^{\circ} \mathrm{C}$ and $1315^{\circ} \mathrm{C}$, respectively.

Discharge voltage results presented in Figure 8 indicate that for all discharge current operating conditions, the discharge voltage decreased with increasing flow rate, which is typical and is similar to that have been previously reported by others. ${ }^{14,15,16,23}$ Cathode-to-ground voltage results in Figure 8 indicate that, in general, the cathode-toground voltage became more negative as the flow rate was increased. At a flow rate of $19 \mathrm{sccm}$, configuration 1 operated in plume mode for all discharge currents. ${ }^{22}$ As the flow rate was increased, the cathode started to transition to spot mode and the cathode-to-ground voltage became more negative. ${ }^{22}$ For discharge currents between 50 and 100 A, the cathode fully transitioned to spot mode at $37 \mathrm{sccm}$. For discharge currents of $125 \mathrm{~A}$ and $150 \mathrm{~A}$, the cathode was in spot mode at $46 \mathrm{sccm}$. Finally, for discharge currents of $100 \mathrm{~A}$ and higher, the cathode plume had a jet like structure at flow rates above 46 sccm, as is shown in Figure 9.

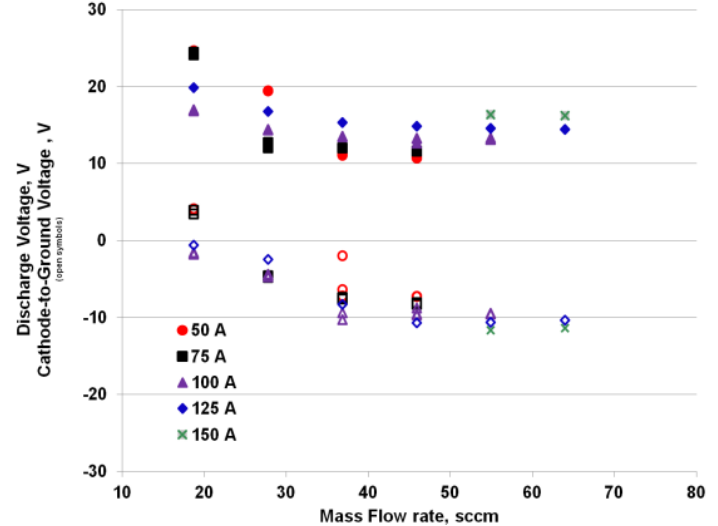

Figure 8. Discharge and cathode-to-ground voltage variation with mass flow rate for various discharge current magnitudes (closed symbols are discharge voltage, open symbols are cathode-to-ground voltage).

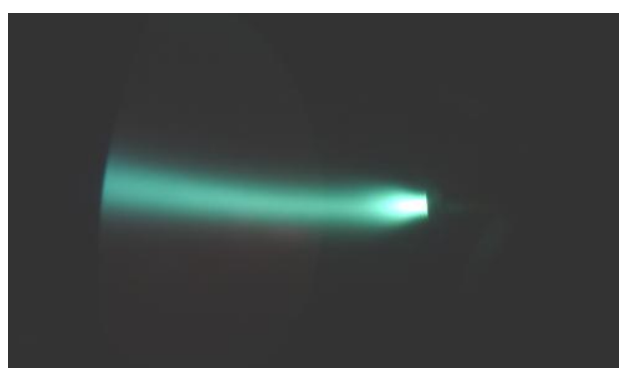

Figure 9. Configuration 1 HCA operating in VF8 at a discharge current of $100 \mathrm{~A}$.

\section{B. Configuration 2}

Configuration 2 assembly is based on configuration 1 except for two major differences:

- Configuration 2 cathode plate orifice diameter is $17 \%$ greater than that of configuration 1 ; and

- Configuration 2 emitter is $33 \%$ shorter than configuration 1.

Configuration 2 cathode and anode placement was identical to that of configuration 1. Table 3 summarizes configuration 2 test conditions.

Table 3: Configuration 2 test conditions.

\begin{tabular}{|c|c|c|c|c|c|c|c|}
\hline \multirow{2}{*}{$\begin{array}{c}\text { Flow rate, } \\
\text { sccm }\end{array}$} & \multicolumn{7}{|c|}{ Discharge Current, A } \\
\hline & 50 & 60 & 70 & 80 & 90 & 100 & 125 \\
\hline 19 & $\bullet$ & $\bullet$ & $\bullet$ & $\bullet$ & $\bullet$ & $\bullet$ & \\
\hline 28 & $\bullet$ & $\bullet$ & $\bullet$ & $\bullet$ & $\bullet$ & $\bullet$ & \\
\hline 37 & $\bullet$ & $\bullet$ & $\bullet$ & $\bullet$ & $\bullet$ & $\bullet$ & $\bullet$ \\
\hline 46 & & & & & & $\bullet$ & \\
\hline
\end{tabular}

Configuration 2 test results are presented in Figures 10, 11, and 12. Figure 10 shows the cathode orifice plate tip temperature variation with flow rate for the different discharge currents. Figure 11 shows the cathode orifice plate tip temperature variation with discharge current for the various flow rates. Figure 12, shows how the discharge voltage and cathode-to-ground voltage varied with flow rate for the various cathode discharge currents. No keeper 
voltage profiles are presented here since the keeper variations were minimal. During configuration 2 test campaign, the keeper voltage varied between $1.5 \mathrm{~V}$ and $2.3 \mathrm{~V}$. Monitored keeper-to-cathode voltage oscillations had a peakto-peak magnitude of approximately $1 \mathrm{~V}$. Similar to configuration 1, configuration 2 was operated for a total of approximately 70 hours. The cathode was operated at discharge currents $\geq 100 \mathrm{~A}$ for approximately 45 hours.

Experimental results presented in Figures 10 and 11 indicate, in general, that the cathode orifice plate tip temperature increased with increased cathode flow rate at the various operating discharge currents. Configuration 2 cathode orifice plate tip temperatures were, in general, $70^{\circ} \mathrm{C}$ to $100{ }^{\circ} \mathrm{C}$ lower than the corresponding configuration 1 values.

Discharge voltage results presented in Figure 12 indicate that for all discharge current operating conditions, the discharge voltage decreased with increased flow rate, which is similar to configuration 1 results. In addition, the discharge voltages of configuration 2 operation were similar to that of configuration 1. Cathode-to-ground voltage results in Figure 12 indicate that, in general, the cathode-to-ground voltage became more negative as the flow rate was increased, also similar to configuration 1. At a flow rate of $19 \mathrm{sccm}$, the cathode operated in plume mode for all discharge currents. As the flow rate was increased, the cathode started to transition to spot mode and the cathode-toground voltage became more negative. For discharge currents between $50 \mathrm{~A}$ and $100 \mathrm{~A}$, the cathode fully transitioned to spot mode at $37 \mathrm{sccm}$.

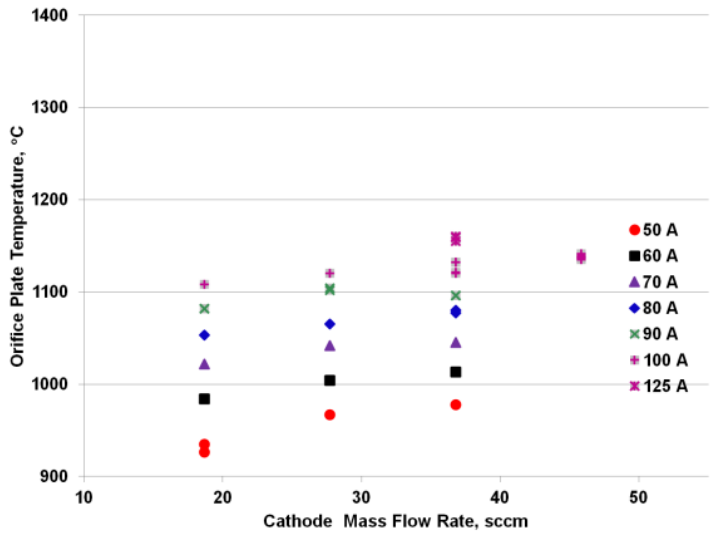

Figure 10. Configuration 2 cathode orifice plate tip temperature variation with mass flow rate for various discharge currents.

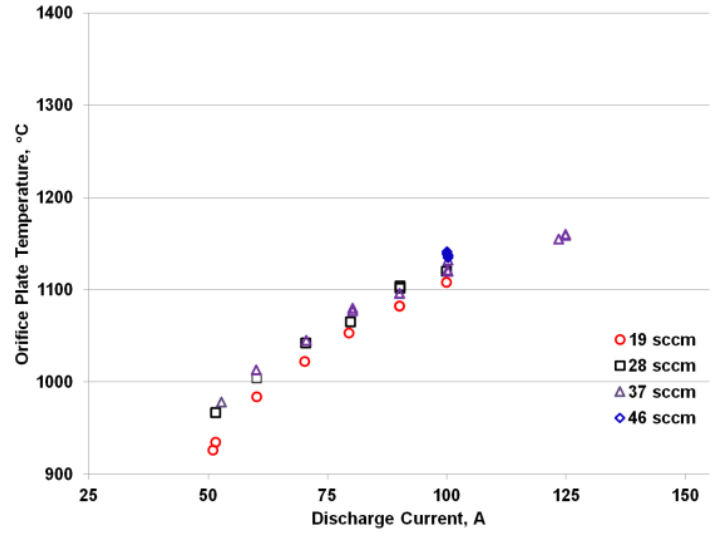

Figure 11. Configuration 2 cathode orifice plate tip temperature variation with discharge current for various mass flow rates.

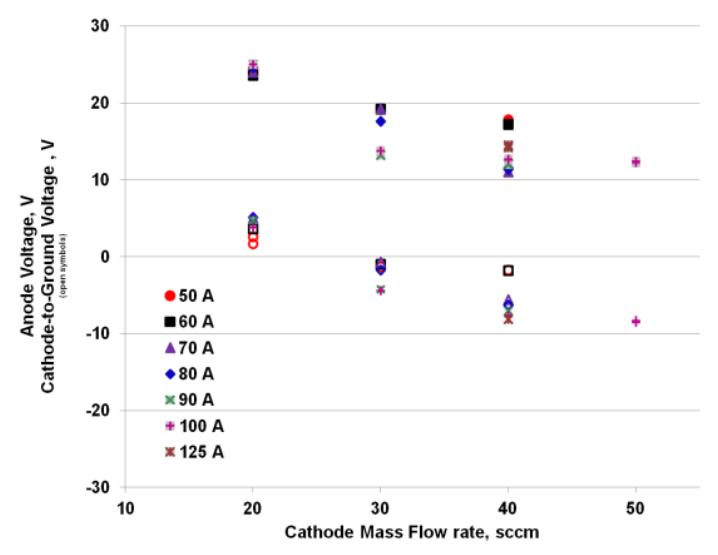

Figure 12. Discharge and cathode-toground voltage variation with mass flow rate for various discharge current magnitudes (closed symbols are discharge voltage, open symbols are cathode-toground voltage). 


\section{Configuration 3:}

Configuration 3 HCA incorporated a novel emitter configuration with enhanced emission area. Configuration 3 utilized an identical design as the NEXT DCA except that it employed a novel emitter configuration. Configuration 3 tests were performed at xenon flow rates between 8 to $21 \mathrm{sccm}$. Configuration 3 design philosophy was aimed at attaining a uniform temperature distribution along the emitter surface resulting in more uniform thermionic electron emission. Figure 13 compares the cathode orifice plate tip temperatures of configuration 3 to that of a laboratory NEXT DCA. As Figure 13 shows, configuration 3 is operating about $50^{\circ} \mathrm{C}$ to $100{ }^{\circ} \mathrm{C}$ cooler than the NEXT DCA, yielding a significant improvement in the life for the emitter. The configuration 3 novel emitter design allows for much higher current cathodes in compact configurations.

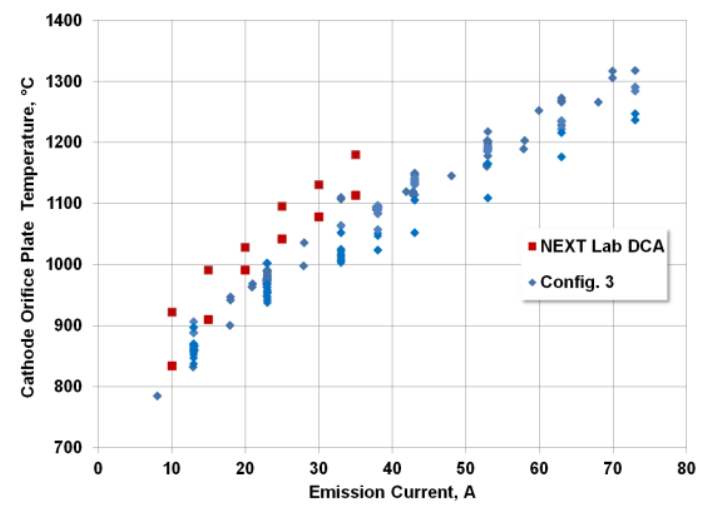

Figure 13. Comparison of cathode orifice plate tip temperatures between configuration 3 and NEXT DCA.

\section{Discussion of Results}

\section{A. Emitter Temperature}

Results presented in Figures 6 and 10 show that the cathode orifice plate tip temperature typically increased with flow rate for configurations 1 and 2 . This trend has been reported by others and was expected. ${ }^{14,15,16,25,26}$ Increasing the cathode flow rate results in increased plasma density inside the emitter; this results in increased plasma fluxes to the emitter surface which slightly increases the emitter temperature. ${ }^{26}$ Although there exists no direct emitter surface temperature measurements for high current cathodes (> 50 A), previous studies have used the cathode orifice plate tip temperature as a measure and indicator of the peak emitter temperature. ${ }^{13,14,15,16}$ Direct emitter surface temperature measurements were performed by Polk et al. on a NEXT NCA type cathode. ${ }^{23}$ The measurements indicated that indeed the cathode orifice plate tip temperature is an indicator of the peak emitter temperature in most cases. ${ }^{22}$ Although this has not been demonstrated for high current cathodes yet, it is assumed in this study that the measured cathode orifice plate tip temperature represents the peak temperature inside the emitter. It is recognized that the emitter temperature depends on a number of factors: the material properties, the contact area between the emitter and cathode orifice plate, radiation losses and heating from the plasma, to name a few. We plan to account for these factors in our future investigations of this cathode, but in this preliminary analysis, we are only concerned with general trends. Additionally, since the ensuing discussion aims to determine and discern whether configuration 2 emitter resulted in a more uniform temperature distribution compared to configuration 1 emitter, one could argue that as long as the same assumptions in our analysis are applied to both configurations, our findings will still provide valid insights regarding the effectiveness of configuration 2 emitter in reducing and minimizing the temperature gradient that typically exists in SOA emitter configurations.

Non-uniform emitter surface temperatures can adversely affect cathode life. Polk et al. have shown that the temperature distribution along the length of the NEXT NCA type cathode emitter varied by as much as $240{ }^{\circ} \mathrm{C} .{ }^{23}$ Having such a temperature gradient along the emitter surface will result in a non-uniform current emission along the emitter length. This non-uniform current emission along the emitter will cause elevated impregnate depletion rates by the cathode orifice plate and much lower impregnate depletion rates in the cooler emitter sections. Because cathode ignition relies mostly on the emitter portion near the cathode orifice plate, accelerated impregnate depletion there will result in a higher work function and elevated emitter surface temperatures. Due to the higher work function near the cathode orifice plate, cathode ignition will eventually require higher voltages and that will ultimately lead to even higher emitter operating temperatures by the cathode orifice plate and eventual cathode failure as was seen by Verhey. ${ }^{11}$

Figure 14 compares the cathode orifice plate tip temperatures for configurations 1 and 2 at $50 \mathrm{~A}$ and $100 \mathrm{~A}$. Configurations 1 and 2 test results at $100 \mathrm{~A}$ and $37 \mathrm{sccm}$ indicate that configuration 2 cathode orifice plate tip temperature is $70{ }^{\circ} \mathrm{C}$ lower than that for configuration 1 . As noted earlier, configuration 2 orifice plate diameter is $17 \%$ larger than that of configuration 1. Previous studies have shown that increased cathode orifice diameters will result in reduced cathode orifice plate tip temperatures. ${ }^{13,15}$ To determine the cathode orifice plate tip temperature 
reduction due to the increased cathode orifice size would require testing of a new cathode configuration that utilizes configuration 2 novel emitter and configuration 1 cathode orifice diameter. Manufacturing, assembly, and testing of a new cathode configuration is not feasible, so numerical simulations with JPL's OrCa2D code will be used to help understand and elucidate configuration 1 and 2 test results at the different operating conditions. ${ }^{24}$ Both configurations 1 and 2 demonstrated lower cathode orifice plate temperatures than what have been previously demonstrated at NASA GRC. Comparing configurations 1 and 2 cathode orifice plate tip temperatures at $100 \mathrm{~A}$ to test results of previously tested high current cathode configurations at NASA GRC shows that configurations 1 and 2 cathode orifice plate tip temperatures were $200{ }^{\circ} \mathrm{C}$ to $270{ }^{\circ} \mathrm{C}$ lower than what was measured by Carpenter et al. in $2001^{14}$ and were approximately $100^{\circ} \mathrm{C}$ to $170{ }^{\circ} \mathrm{C}$ lower than what was measured by John et al. in $2005 .^{15}$ The results obtained with configurations 1 and 2 indicated that proper sizing of the cathode tube and emitter is critical in attaining the desired peak emitter temperature.

A simplified analysis of configurations 1 and 2 results was performed to determine if configuration 2 novel emitter did attain a more uniform emitter temperature distribution compared to configuration 1 . The analysis evaluated whether a more uniform emitter temperature distribution could cause higher internal plasma potentials which may lead to higher cathode erosion rates. The discharge current density $\left(J_{d}\right)$ produced by the cathode is composed of the electron emission current density $\left(J_{e m}\right)$, the emitter electron return current density $\left(J_{e}\right)$, the emitter ion return current density $\left(J_{i o n}\right)$, and the discharge current density emitted from the upstream orifice plate open area $\left(J_{\text {orif }}\right)$. This is shown in Eq. 4 below:

$$
J_{d}=J_{e m}-J_{e}+J_{\text {ion }}+J_{\text {orif }}
$$

For this analysis, $J_{i o n}$ and $J_{\text {orif }}$ will be ignored. To perform the analysis, the electron emission current was calculated using the Richardson-Duchman equation where the constant emitter temperature term is replaced with a term that takes into account the temperature variation along the emitter surface. This is shown in Eq. 5 below:

$$
J_{e m}(x)=A_{o} T(x)_{\text {emit }} e^{\frac{-q_{e}\left(\varphi_{O}+\alpha T(x)_{\text {emit }}\right)}{k T(x)_{\text {emit }}}}
$$

The electron return current to the emitter is calculated by Eq. 6 below:

$$
J_{e}(x)=\frac{n_{e}(x) \cdot q_{e} \cdot \sqrt{8 k T_{e}(x) / \pi m_{e}}}{4} \cdot e^{\left(-q_{e} \cdot \phi(x) \text { sheath } / k T_{e}\right)}
$$

Where $\mathrm{n}_{\mathrm{e}}(\mathrm{x})$ is the electron density along emitter surface, $\mathrm{T}_{\mathrm{e}}(\mathrm{x})$ is the electron temperature along emitter surface, and $\phi_{\text {sheath }}(\mathrm{x})$ is the plasma potential distribution on the emitter surface.

A first estimate of the emitter temperature gradient inside the emitter can be obtained by assuming that the discharge current is entirely comprised of the electron emission current $\left(J_{d}=J_{e m}(x)\right)$. Then using Eqs. 4 and 5 and the measured cathode orifice plate tip temperature, the temperature gradient along the emitter length is calculated. The analysis then suggests that configuration 1 had a $300{ }^{\circ} \mathrm{C}$ surface temperature variation along its length, whereas configuration 2 had a minmal surface temperature variation along the emitter length.

Adding the contributions from the electron return current to the discharge current (Eq. 4) requires

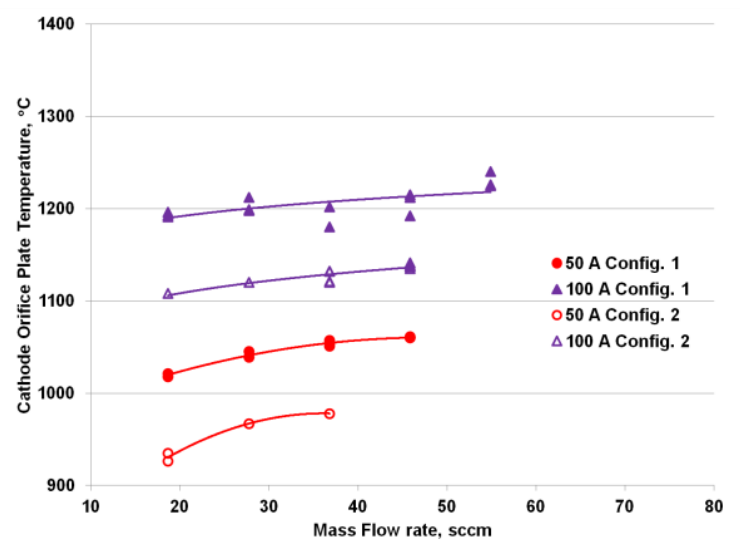

Figure 14. Configurations 1 and 2 cathode orifice plate tip temperature variation with flow rate for discharge currents of 50 and $100 \mathrm{~A}$.

estimates of the electron temperature and number density magnitudes and profiles their perspective axial profiles along the emitter surface. No such data exist for this hollow cathode, so the preliminary analysis herein will rely on internal experimental centerline plasma measurements that were obtained on a comparably sized high current cathode. In 2011, Goebel et al. measured the internal plasma density, electron temperature, and plasma potential along the centerline of a $1.5-\mathrm{cm} \mathrm{LaB}_{6}$ hollow cathode operating at 100 A discharge current at flow rates of $8 \mathrm{sccm}$, $10 \mathrm{sccm}$, and $12 \mathrm{sccm} .{ }^{25}$ Goebel found that at a discharge current of $100 \mathrm{~A}$ and a flow rate of $12 \mathrm{sccm}$, the electron temperature varied between $1.5 \mathrm{eV}$ and $2.8 \mathrm{eV}$ along the emitter centerline axial position, and that the plasma 
density varied between $1 \times 10^{20} \mathrm{~m}^{-3}$ and $8 \times 10^{20} \mathrm{~m}^{-3}$ along the emitter centerline axial position. For the present study, it is recognized that conditions in our cathodes were different than those used by Goebel, but in the absence of direct measurements and/or detailed numerical simulations and for purposes of the preliminary analysis presented below, the plasma conditions in Goebel's cathode are to order of magnitude representative of conditions in our cathodes. Also, the peak plasma potential is assumed to occur near the cathode plate and drops to $60 \%$ of its peak value at the emitter upstream end; this profile is similar to what Goebel observed with the $1.5-\mathrm{cm}$ and $2.0-\mathrm{cm} \mathrm{LaB}{ }_{6}$ cathodes. ${ }^{25}$ Finally, we recognize that the centerline data is not representative of conditions near the emitter surface, but sensitivity analysis calculations indicated that lowering the density magnitude did not have a significant impact on the conclusions of this preliminary analysis.

Analysis of configurations 1 and 2 experimental results was performed using Eqs. 4-6 and using the plasma properties listed in the previous paragraph. Configuration 1 analysis results indicated that the peak plasma potential was around $15 \mathrm{~V}$ and that the temperature variation across the emitter length was approximately $240{ }^{\circ} \mathrm{C}$ (instead of the $300{ }^{\circ} \mathrm{C}$ found when neglecting the return electron current). Configuration 2 analysis results indicated that the peak plasma potential was around $20 \mathrm{~V}$ and that there was no temperature variation along the emitter length.

Finally, the prediction of the plasma potential is very sensitive to the peak emitter temperature, the electron temperature, and the prescribed plasma potential profile. The conclusions of the analysis are that configurations 1 and 2 peak plasma potentials varied by approximately $5 \mathrm{~V}$, and that measurements of the emitter temperature and the emitter region centerline plasma properties are required. These measurements along with detailed numerical modeling (using JPL's OrCa2D) will aid in precisely determining if configuration 2 emitter had a more uniform temperature distribution when compared to configuration 1.

\section{B. Discharge Voltage}

The main contributors to the discharge voltage include the plasma potential inside the cathode, the resistive drop across the cathode orifice, and the discharge plasma potential. Analysis of the discharge voltage profiles for configurations 1 and 2, presented in Figures 8 and 12, respectively, reveals that the discharge voltage increased monotonically with reduced cathode flow rate at a given discharge current. This trend is similar to what was measured by previous hollow cathode studies. ${ }^{13,14,15,16,25,26}$ The increase is discharge voltage with reduced flow rates could be attributed to the fact that as the plasma density in the emitter region is reduced, the plasma potential increases to maintain the heat flux to the emitter. However, as the cathode transitions to plume mode, the anode fall voltages will increase in order to support the discharge current. Comparisons of the discharge voltage profiles for configurations 1 and 2 for discharge currents of $50 \mathrm{~A}$ and $100 \mathrm{~A}$ are presented in Figure 15 and indicate that it is difficult to discern any distinguishable trends between configurations 1 and 2 .

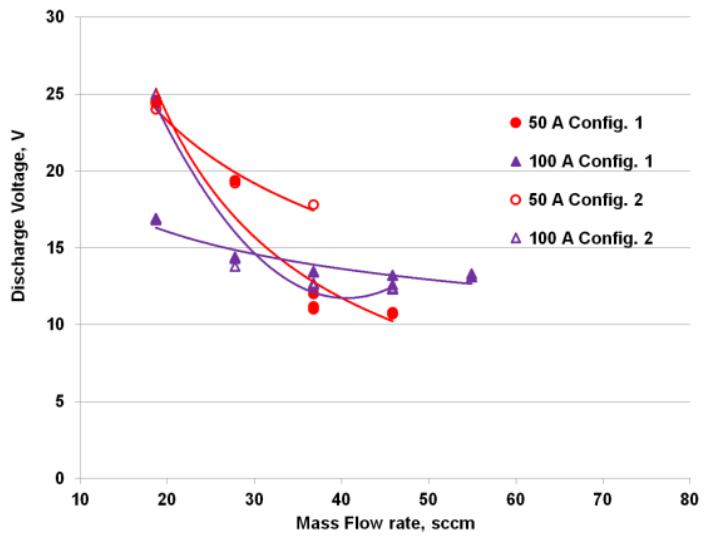

Figure 15. Configurations 1 and 2 discharge voltage variation with flow rate for discharge currents of 50 and $100 \mathrm{~A}$.

\section{Erosion}

Previous high current hollow cathode tests have shown that significant cathode and keeper orifice and anode erosion occurs when operating at high discharge currents. ${ }^{13,14,25,27}$ Cathode orifice plate erosion was observed by Brophy et al. ${ }^{27}$ This was due to the high orifice plate current density which results in a large potential drop across the orifice and leads to higher ion energies. ${ }^{27}$ Goebel et al. observed that significant amounts of the copper anode were sputter eroded close to the cathode, Goebel postulated that was due to high energy ions that are produced downstream of the keeper plate. ${ }^{25}$ During the test campaign reported herein, measured cathode keeper orifice diameters had not changed after over 70 hours of accumulated operation. In addition, a visual inspection of the molybdenum anode did not show any signs of sputter erosion. Again, detailed plasma measurements in the plume of the high current cathode and extended duration operation are required to assess whether energetic ion production is occurring in these high-current cathodes. 


\section{Conclusions}

Tests of three high current cathode configurations were performed. Two of the cathode configurations employed novel emitter configurations that were intended to result in a more uniform temperature distribution along the emitter surface than the state-of-the-art. Evaluation of the candidate novel emitter configurations indicated that lower operating cathode orifice plate tip temperatures were attained than state-of-the-art cathodes.

One cathode configuration, configuration 2, attained a cathode orifice plate tip temperature of $1132{ }^{\circ} \mathrm{C}$ when operating at a discharge current of $100 \mathrm{~A}$, which is more than $250{ }^{\circ} \mathrm{C}$ lower than what was previously demonstrated at NASA GRC. A preliminary analysis of configuration 2 test results indicated that a uniform emitter temperature was realized along the emitter surface.

Near-term future testing will include operating configuration 2 for extended durations. In addition, detailed emitter temperature and plasma measurements inside the hollow cathode emitter region have to be performed. These measurements will be supplemented by extensive physics based hollow cathode modeling.

\section{Acknowledgments}

The authors would like to thank and acknowledge the Office of the Chief Technologist for funding this work as well as Timothy Smith for serving as the Project Manager. The authors would also like to thank Mike Pastel, Kevin McCormick, and George Readus for their aid in manufacturing and testing of the high current cathode assemblies.

\section{References}

${ }^{1}$ Dudzinski, L., et al., "Design of Solar Electric Propulsion Transfer Vehicle for a Non-Nuclear Human Mars Exploration Architecture," IEPC Paper 99-181, October 1999.

${ }^{2}$ Oleson, S.R., et al., "Advanced Propulsion for Space Solar Power Satellites," AIAA Paper 99-2872, June 1999.

${ }^{3}$ Oleson, S.R., et al., "Mission Advantages of Constant Power Variable Specific Impulse Electrostatic Thrusters," NASA TM-2000-210477, March 2000.

${ }^{4}$ Jankovsky, R.S., et al., “NASA’s Hall Thruster Program 2002,” AIAA Paper 2002-3675, July 2002.

${ }^{5}$ Manzella, D. H., et al., "Laboratory Model 50 kW Hall Thruster," AIAA Paper 2002-3676, July 2002.

${ }^{6}$ George Soulas, Haag, T. W., Herman, D. A., Huang, W., Kamhawi, H., and Shastry, R.," Performance Test Results of the NASA-457Mv2 Hall Thruster," AIAA Paper 2012-3940, July 2012.

${ }^{7}$ Peterson, P. Y., "Performance and Wear Characterization of a High Power High-Isp Hall Thruster," AIAA Paper 2005-4243, July 2005.

${ }^{8}$ Kamhawi, H., Haag, T. W., Jacobson, D. T., and Manzella, D. H., "Performance Evaluation of the NASA-300M 20 kW Hall Effect Thruster," AIAA Paper 2011-5521, July 2011.

${ }^{9} \mathrm{http} / / / \mathrm{www}$. nasa.gov/exploration/new_space_enterprise/home/heft_summary.html

${ }^{10}$ Brophy, J.R., et al., "300-kW Solar Electric Propulsion System Configuration for Human Exploration of Near Earth Asteroids," AIAA Paper 2011-5514, August 2011.

${ }^{11}$ Verhey, T. R., "28,000 Hour Xenon Hollow Cathode Life Test Results," IEPC Paper 97-168, November 1997.

${ }^{12}$ Shastry, R., Herman, D.A., Soulas, G.C., and Patterson, M.J., "NASA's Evolutionary Xenon Thruster (NEXT) Long-Duration Test as of $736 \mathrm{~kg}$ of Propellant Throughput," AIAA Paper 2012-4023, July 2012.

${ }^{13}$ Rawlin, V.K., et al., "High Current Hollow Cathodes for Ion Thrusters," AIAA Paper 87-1072, May 1987.

${ }^{14}$ Carpenter, C. B., and Patterson, M. J., "High-Current Hollow Cathode Development," IEPC Paper 01-274, October, 2001.

${ }^{15}$ John, J. W., Sarver-Verhey, T. R., and Kamhawi, H., "High Current Cathode Development for 50 kW Class Hall Thruster," AIAA Paper 2005-4244, July 2005.

${ }^{16}$ Van Noord, J. L., Kamhawi, H., and McCwen, H. K., "Characterization of a High Current, Long Life Hollow Cathode," IEPC Paper 05-321, October 2001.

${ }^{17}$ Cronin, J.L., "Modern Dispenser Cathodes", IEEE Proceedings, 128, 1, pp. 19-32, 1981.

${ }^{18}$ Palluel, P. and Shroff, A. M., "Experimental Study of Impregnated-Cathode Behavior, Emission and Life," Journal of Applied Physics, Vol. 51 No. 5, 1980, pp. 2894-2902.

${ }^{19}$ Palluel, P., and Shroff, A.M., "Experimental Study of Impregnated-Cathode Behavior, emission, and Life,", Journal of Applied Physics 51 (5), May 1980.

${ }^{20}$ Sengupta, A., Brophy, J, Anderson, J., Garner, C., Banks, B., and de Groh, K., "An Overview of the Results from the 30,000 Hr Life Test of Deep Space 1 Flight Spare Ion Engine," AIAA Paper 2004-3608, July 2004. 
${ }^{21}$ Sarver-Verhey, T. R., "Scenario for Hollow Cathode End-of-Life", NASA Contractor Report, NASA/CR-2000209420, Jan. 2000.

${ }^{22}$ D.M. Goebel, K. Jameson, I. Katz and I. Mikellides, "Plasma Potential Behavior and Plume Mode Transitions in Hollow Cathode Discharges" IEPC Paper 2007-27, September 2007.

${ }^{23}$ Polk, J., Marrese, C., Dang, L., Johnson, L., and Thornber, B., "Temperature Distribution in Hollow Cathode Emitters," AIAA Paper 2004-4116, July 2004.

${ }^{24}$ Mikellides, I. G., et al., "Plasma Processes Inside Orificed Hollow Cathodes", Physics of Plasmas, 13, 063504 (2006).

${ }^{25}$ Goebel, D. M. and Chu, E., "High Current Lanthanum Hexaboride Hollow Cathodes for High Power Hall Thrusters", IEPC Paper 2011-053, September 2011.

${ }^{26}$ Polk, J. E., et al., "Characterization of Hollow Cathode Performance and Thermal Behavior," AIAA Paper 20065150.

${ }^{27}$ Brophy, J. R., and Garner, J. E., “Tests of High Current Hollow Cathode Cathodes for Ion Engines,” AIAA Paper 88-2913, July 1988. 